\title{
Estimating the economic value of viewing griffon vultures Gyps fulvus: a Travel Cost Model study at Gamla Nature Reserve, Israel
}

\author{
Nir Becker, Moshe Inbar, Ofer Bahat, Yael Choresh, Gil Ben-Noon and Omer Yaffe
}

\begin{abstract}
The proper valuation of non-market environmental commodities such as wildlife viewing has significant policy implications. We implemented the Travel Cost Method (TCM) to estimate the value of viewing threatened Eurasian griffon vulture Gyps fulvus by the public at Gamla Nature Reserve, northern Israel. We used the zonal TCM, where concentric zones were defined around the site such that the cost of travel from all points in a given zone was approximately constant. We generated a visit-distance function and used it, based on 143 questionnaires, to derive the demand function for the site from which a monetary value could be estimated. The potential annual benefit of Gamla was estimated to be NIS 5.5-6.0 million (USD 1.1-1.2 million). The annual
\end{abstract}

economic value of Gamla to the visiting public is approximately five times higher than the current revenue, and $85 \%$ of the visitors to Gamla came to view vultures. This information can be used to estimate the benefits of further investment in Gamla Nature Reserve, to price this site according to demand if there are budget limits, and in particular to invest in the protection of vultures and other threatened species.

Keywords Gamla Nature Reserve, griffon vulture, Gyps fulvus, non-market goods, Travel Cost Method, wildlife viewing.

This paper contains supplementary material that can only be found online at http:/ / journals.cambridge.org

\section{Introduction}

The proper valuation of non-market environmental commodities, such as the recreation value of wildlife viewing or of a site such as a nature reserve, has significant policy implications. Until recently such commodities have been assigned zero or low values due to the difficulties involved in assigning economic value. Failure to properly account for the values of some environmental resources, however, has resulted in decisions that have had negative implications for the environment and for

Nir Becker (Corresponding author) Department of Economics and Management, Tel-Hai College, Upper Galilee, 12210, Israel, and Natural Resources and Environmental Research Center, University of Haifa, Haifa, 31905, Israel. E-mail nbecker@econ.haifa.ac.il

Moshe Inbar Department of Environmental \& Evolutionary Biology, University of Haifa, Haifa, 31905, Israel.

Ofer Bahat Birds of Prey Research and Conservation Project, Israel Nature Reserves and Parks Authority and The Society for Protection of Nature in Israel, 24 Haoranim St., Zichron-Yaakov, 30900, Israel.

Yael Choresh Department of Natural Resources and Environmental Management, University of Haifa, Haifa, 31905, Israel.

Gil Ben-Noon Gamla Nature Reserve, Israel Nature Reserves and Parks Authority, P.O. Box 70, Katzrin, 12900, Israel.

Omer Yaffe Department of Economics and Management, Tel-Hai College Upper Galilee, 12210, Israel.

Received 5 March 2004. Revision requested 25 August 2004 Accepted 20 December 2004 society. In the last 3 decades valuation studies have been carried out to put a price tag on resources such as parks and endangered species (Garrod \& Willis, 2001).

In this study we used the Travel Cost Method (TCM) to estimate the use value of viewing vultures in their natural habitat. Our purpose is to present policy makers with an estimate of the value of Gamla Nature Reserve, Israel, to the visiting public, with an emphasis on viewing and protecting the Eurasian griffon vulture Gyps fulvus. If the results indicate that benefits outweigh costs, the study will serve as an indicator of the need to further invest in protecting this species. This value is a lower limit, as the site also has non-use values that were not measured in this study.

\section{The Eurasian griffon vulture}

The Eurasian griffon vulture is a threatened species throughout its breeding range except on the Iberian Peninsula, which contains the majority of the global population (Mundy et al., 1992). Although it is not on the IUCN Red List (IUCN, 2004), the species is categorized as Vulnerable in Israel (Pervolotsky \& Dolev, 2002). The griffon vulture is an obligatory scavenger now dependent mostly on domestic ungulates; it was once abundant in Israel (Tristram, 1885) but, despite being protected by law, its population declined dramatically since the 1970 s due to the large-scale use of pesticides. Declines often happen when birds ingest prey that were the intended 
target of pesticides, and subsequently die of secondary toxicosis (Shlosberg, 2001). There are also other conservation problems, most of them human-related (Mendelssohn \& Leshem, 1983). At present, the Israeli population of this species is restricted to four areas: the Golan and Galilee in the north, and the Judean and Negev deserts in the south. The breeding population comprises 100-140 pairs and the total number of individuals is $300-460$ (O. Bahat, unpubl. data). Conservation efforts include annual censuses of breeding pairs, supplementary feeding stations, ringing and radio tracking of nestlings and adult birds, a captive breeding and reintroduction programme, directing publicity towards hunters and farmers, a joint working programme with the Israel Electric Company to minimize electrocutions and with the Israeli Air Force to prevent collisions between birds and aircraft. These efforts are constantly being reviewed, especially in times of budget limitations and when there is a need to establish whether these measures are in accordance with public preferences. Griffon vultures are majestic birds with a $2.8 \mathrm{~m}$ wingspan, often seen soaring above the cliffs of their breeding colony, and visitors to Gamla spend a lot of time at the observatory viewing and photographing vultures.

\section{The Travel Cost Method}

The Travel Cost Method was first suggested by Harold Hotelling in the late 1940s (Kolstad, 2000). The US National Park Service solicited advice from economists on methods for quantifying the value of specific park properties. The purpose was to show that parks and other outdoor recreation sites have benefits higher than the cost of protecting them using taxpayers' money. Hotteling designed the idea of travel cost as a reflection of the value visitors place on a park. The method has been frequently used, especially in the late 1960s (Clawson \& Knetch, 1966), mainly to value the recreational benefits of a park but also used for other purposes such as valuing clean air, water and wetlands (Ward \& Beal, 2000).

Navrud \& Mungatana (1994) used TCM to estimate the value of preserving the current flamingo population in Lake Nakuru National Park in Kenya, with respondents asked what percentage of their time in the Park was spent viewing and photographing flamingos. The annual recreational value of wildlife viewing in the Park was found to be USD 1.5-7.5 million, with the flamingos accounting for more than one-third of this. In 1991 Kenya Wildlife Service's total revenue from entrance fees, royalties from hotels and lodges and camping fees was c. $5-10 \%$ of the observed recreational value, i.e. the Park had a much larger economic potential than was actually realized. Protecting the flamingos contributes both to nature conservation and financially to the social welfare of the country.
Brown (1993) used TCM to estimate the benefit derived from safaris in Kenya, and from that calculated the value of viewing elephants that was over and above the travel costs. We used the same model in our study, while trying to extract the viewing value of vultures by asking visitors to rank the different attributes of Gamla. In Kenya it was found that viewing elephants was the source of $12.6 \%$ of the total value of a trip. Applying that share to the estimated economic value of safaris yielded a viewing value for elephants of USD 23-27 million per year. By demonstrating the economic loss associated with declines in elephant populations the results were used to marshal the resources necessary to reduce poaching.

The basic underlying assumption of TCM is that the costs an individual incurs in visiting a site reflects a lower limit of the person's valuation of the site. The recreational value of a park is indicated by how many people travel how far to visit it, because the cost of travel is effectively the cost of a visit. By asking visitors questions relating to where they have travelled from and the costs they have incurred, a distance-visit function can be estimated. A demand curve for the park can then be generated by hypothetically raising the cost of the visit and finding out how this affects total visits to the park. This is done by using the distance-visit function. The curve fitted to this function is downward sloping, with admission price or apparent travel cost inversely related to number of visits As the travel cost is raised only those living nearest the site would still find it relevant to visit. The information requested in a TCM survey includes travel costs (petrol, food and other travel-related expenses, time spent travelling to the site and time spent on site), entrance fee, alternative sites on that trip, personal motivation and socio-economic characteristics (Ward \& Beal, 2000).

There are two forms of TCM, the Zonal Travel Cost Method (ZTCM) and the Individual Travel Cost Method (ITCM). In the ZTCM, concentric zones are defined around a site such that the cost of travel from all points in a given zone is approximately constant. Visitors to the park are grouped according to their zone of origin. By comparing the cost of coming from a zone with the number of people who come from it and the population of that zone, one can plot a point for each zone. A function can then be fitted to generate the distance-visit function $V h / N h=f(C h, X h)$, where $V h=$ number of visits from zone $h, N h=$ population of zone $h, C h=$ travel cost from zone $h$, and $X h=$ a vector of socio-economic variables.

Socio-economic variables are used to control for other motivations to visit the site, such as education and income. However, if these characteristics are the same over all zones then a hypothetical price rise will affect 
visitation only through the cost component and its associated coefficient.

This function can be used to calculate the effect of raising the price on the total number of visits. By repeatedly raising the price, the demand function to the site can be obtained. As the demand function represents the marginal willingness to pay for the good (i.e. how much one is willing to pay for an additional unit of that good), the total benefit can be obtained by integrating the function. This is especially so when the entrance to the park is free, in which case the total benefit of the park is simply the area under the demand curve (Hacket, 2000). The ITCM is usually better suited for the valuation of natural parks but it requires information about the number of visits to the given site (Hacket, 2000; Lansdell \& Gangadharan, 2003). Implementing the ITCM requires a large sample of visitors that vary in their visitation rate, and as most people visiting Gamla do so only once or twice per year, we used the ZTCM.

Two types of travel costs need to be taken into account: (1) the cost of driving, and (2) the opportunity cost of the time spent on the way to and from the site plus the time spent at the site. Opportunity cost of time is usually measured by the monetary value of what an individual could have been doing with this time, often measured by a fraction of the individual's salary.

\section{Calculations}

We divided the country into 10 concentric zones of $30 \mathrm{~km}$ intervals. The questionnaires were grouped according to the concentric zones, from the nearest to the furthest. The travel cost was calculated per questionnaire as $\left[\frac{\left(P C^{*} k m\right)+\left(T V^{*} h\right)}{N}\right] \alpha$, where $P C=$ petrol cost per $\mathrm{km}$, $\mathrm{km}=$ number of kilometres, $T V=$ cost of time per hour according to the individual's income, $h=$ hours, $N=$ number of adults in the car, and $\alpha=$ visit time to the site as a fraction of the total time of the trip. We calculated an average travel cost for each zone based on the visitors in the sample. The final result was travel cost per capita per questionnaire.

We summed the visits per zone and calculated their ratio in the sample. We then multiplied that ratio by the total number of visits per year to Gamla (Gamla, 2000) to obtain the estimated number of visits from that zone, assuming that visitors to Gamla have the same zonal distribution as the visitors in the sample. We divided the calculated visitors per zone by the population size of the zone to give visits per capita per zone. A regression of this versus average travel cost from each zone gave the distance- visit function $V p C=\alpha+\beta(T C)$, where $V p C=$ visits per capita, $\alpha, \beta=$ coefficients to be estimated, and $T C=$ travel cost.
The distance-visit function can be used to derive the demand function for the site. This is done by increasing the admission price repeatedly and obtaining a predicted number of visits for each zone at the new admission price; the original admission price is usually zero or the actual admission price to the site if there is one. The demand function is derived by regressing the different admission prices on the total number of visits to the site: $V=\alpha+\beta P$, where $V=$ visits, $\alpha, \beta=$ coefficients to be estimated, and $P=$ price.

The last step is to integrate the demand function to get the benefit of the site. This is given by $\int_{P(0)}^{\infty} V \delta p$, where variables are as defined above. We used linear distancevisit and demand functions. Although there is no specific reason to assume that this is better than a semilogarithmic or other function, in a comparative analysis of alternative functional forms, it was found that the linear function was the most valid (Bell \& Leeworthy, 1990).

\section{Data gathering}

Gamla Nature Reserve is in the centre of the Golan Heights in northern Israel, which is one of the largest and most important recreational areas in the country. An average of 100,000 people visit Gamla per year, mainly during the spring and summer (Gamla, 2000). The Reserve offers visitors the sight of the highest waterfall in the country $(51 \mathrm{~m})$, the archaeological site of ancient Gamla, and a field of dolmens. Gamla is the only Reserve in northern Israel where griffon vultures can be observed throughout the year. The cliffs of Gamla are the breeding place of an established griffon vulture colony (Bahat, 1998).

The questionnaire (Appendix 1) was developed so that it would provide the necessary information for calculating travel costs. Information included where people come from, how often they visit Gamla, how many hours they intend to spend on site and in the area, what other sites they plan to visit, how many people are in their party, and some socio-economic details. To extract the value of viewing vultures from the total value of the trip respondents were asked to rank their interest in their visit to Gamla from the variety of attributes the site has.

The questionnaires were distributed among 170 visitors at Gamla, of which 143 (84\%) responses were usable. They were distributed over 6 months (January-June 2002) including winter (with fewer visits), spring and summer (with most of the visits; Gamla, 2000). The questionnaires were distributed during both weekdays and weekends (Gamla, 2000). The visitors usually spend enough time at the shaded observatory to enable them to 
Table 1 Travel distance, number of visits in the sampled population, total population, and visits per capita from each concentric zone (see text for details) around Gamla Nature Reserve.

\begin{tabular}{llcrl}
\hline & $\begin{array}{l}\text { Travel } \\
\text { distance to } \\
\text { Region }\end{array}$ & $\begin{array}{l}\text { Visits in } \\
\text { sample }\end{array}$ & Population & $\begin{array}{l}\text { Visits per } \\
\text { capita }\end{array}$ \\
\hline 1 & 30 & 20 & 34,815 & 0.0636 \\
2 & 60 & 53 & 185,870 & 0.0316 \\
3 & 90 & 152 & 858,564 & 0.0196 \\
4 & 120 & 236 & 649,500 & 0.0402 \\
5 & 150 & 42 & 495,533 & 0.0094 \\
6 & 180 & 138 & $1,333,289$ & 0.0115 \\
7 & 210 & 186 & $1,713,987$ & 0.0120 \\
8 & 240 & 2 & 406,058 & 0.0005 \\
9 & 270 & 9 & 393,778 & 0.0025 \\
10 & 300 & - & 99,557 & - \\
Total & & 838 & $6,170,951$ & 0.0212 \\
\hline
\end{tabular}

complete the questionnaire. A visitor filled in the questionnaire as a representative of the visiting group. Organized groups were excluded because we assumed they did not necessarily decide on the tour destination. We did not encounter any major resistance to filling in the questionnaire and we continued until we had obtained a sufficient number of returned forms. Although this could cause a selection bias it is not a problem in this study, which is based on actual behaviour.

Demographic data was obtained from CBS (2005). The opportunity cost was calculated as the cost of $25 \%$ of a working hour of a given individual (McKean et al., 1995; Garrod \& Willis, 1999; Ward \& Beal, 2000). Working hours were calculated with data obtained from CBS. Travel distance and time was calculated with Mapa (2005), which estimates travel time within Israel. The cost of using a vehicle was calculated according to the commonly cited Heshev database (Katsin, 2002).

\section{Results}

Travel distances, populations and visitation rates are given in Table 1. There was a significant influence of distance on visits per capita (Fig. 1). A regression with the chosen socio-economic variables showed that none of them were significant. Thus the main explanatory variable is distance, which is reflected in travel cost. Average socio-economic values were not different among the zones (95\% two-tailed $t$-test) so we used only the distance, or cost, to obtain the demand function for the site.

The demand function was determined by increasing the admission price repeatedly by intervals of NIS 10, and the variation successfully predicted the number of visits (Fig. 2). Both the intercept and the price coefficient are statistically significant $(P<0.01)$. Based on this regression the value of the site is USD 1.12 million (at USD $1=$ NIS 4.4) compared to the revenue from the entrance fee which is $c$. USD 239,000 per year and a total operating cost of USD 227,000 per year (Gamla, 2000).

\section{Discussion}

Distance of travel, rather than any socio-economic parameters, had the strongest influence on visits per capita. Within the sample, income and education level were similar among the regions but higher on average than the mean values for the entire Israeli population. We therefore omitted these variables to obtain an improved regression. It should be noted that the derived value of the site represents only its use value because the questionnaires were given only to visitors to the site.

This study suggests that Gamla has an economic potential far greater than its realized economic earnings. We assume that this situation is not specific to Gamla but applies to other parks and nature reserves in Israel. These

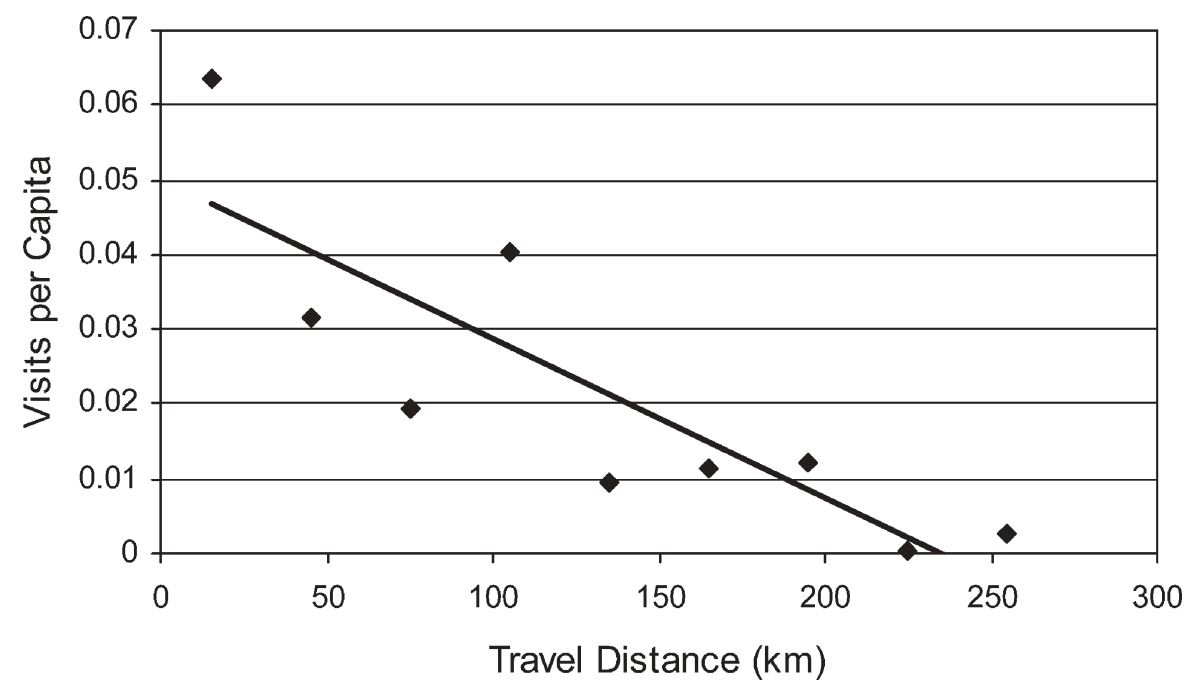

Fig. 1 The dependence of visits per capita on travel distance to Gamla Nature Reserve, where Visits per capita $=0.05-0.00021$ * Distance ( 22 adj. $=0.68)$. 


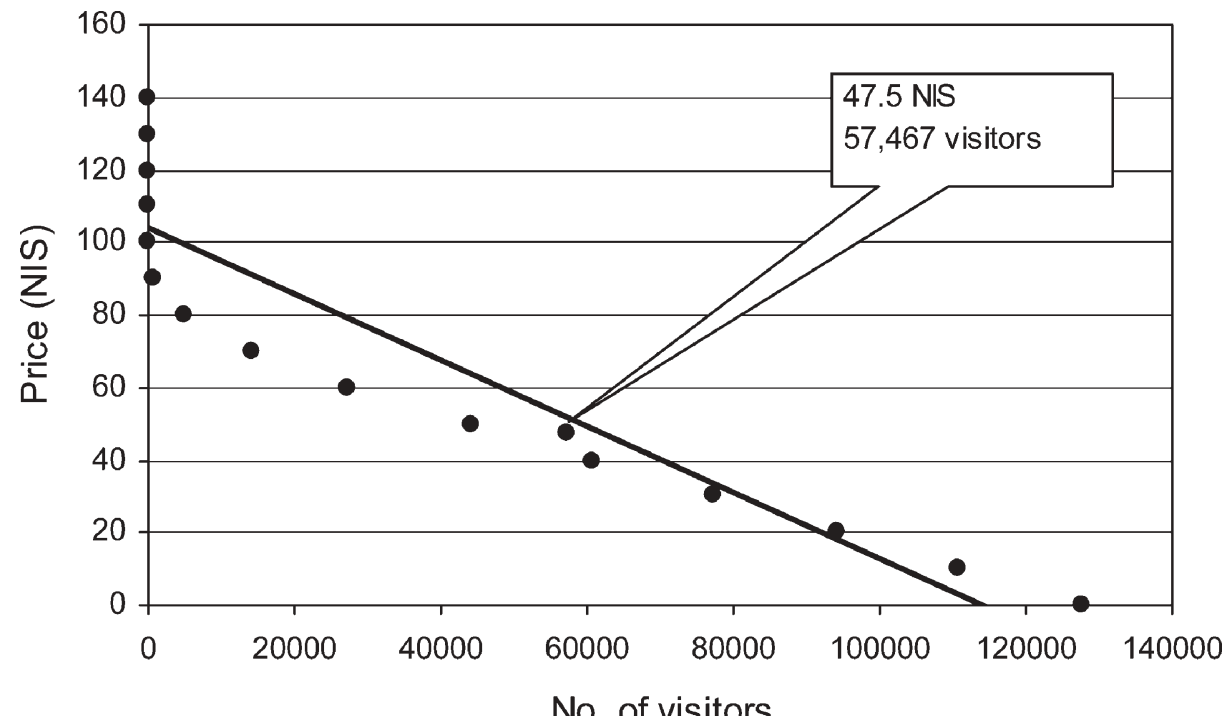

Fig. 2 The demand curve (see text for details) for Gamla Nature Reserve, where Price $=111,417.23-1135.79$ * Number of visits $($ R2 adj. $=0.91)$. results could be of use for making decisions between policy options. Firstly, they could be used to compare alternative development plans. For example, various sites could be ranked according to their consumer surplus, and then investment in expansion determined according to this criterion. This method could also be used to determine investment in different vulture colonies in Israel (there are three major and several minor colonies). Secondly, the TCM results could be used to study the impact of pricing on the Reserve (Willis, 2003), which would be of importance when funding is scarce. One objective of a decision-making authority could be to maximize revenues (usually when the operational and maintenance costs are negligible and therefore revenues serve as profit). However, it should be noted that there are other factors, such as congestion costs and carrying capacity problems, which we have ignored in this research.

A demand function reveals the link between any given price and the quantity associated with it. Multiplying price by quantity yields the revenue, in this case the revenue from a given entrance fee. Using the demand function it is possible to estimate the revenue for any given price, represented by a rectangle created by any pricequantity pair. For a linear demand function, as in this case, the price that maximizes the revenue is exactly at the middle of the curve (Fig. 2), giving the quantity that will yield the largest rectangle. This implies that an increase of the entrance fee to NIS 47.5 would maximize revenue, increasing it to NIS 2.73 million per year, i.e. an increase of $160 \%$ over the current annual revenue of NIS 1.05 million. At this price, however, there will be only 59,584 visitors. This, in turn, reduces the area under the demand curve because it prevents visitors from coming because of a higher entrance fee. In this case the area under the demand curve is reduced by NIS 1.365 million. From a social welfare point of view entrance to the Reserve should be free, since it is a public good and the cost of maintaining it should come from the general budget. The current entrance fee (24 NIS per person) to Gamla is the same as to any other Natural Reserve in the country. This does not, however, indicate any specific management target but an arbitrary fixed price. This is a political issue that we will not discuss, but the options that we have presented should be of use when deciding on a pricing mechanism for this or other reserves. Another pricing mechanism that could be used is one that equates revenues to the cost of maintaining the site, which means zero profit (Willis, 2003). The operational costs at Gamla are 998,000 NIS, which should be equal to the revenue under such a policy. In other words, the above mentioned area of the rectangle should be equal to the operational costs.

Finally, and most relevant as a conservation goal, this analysis could be used to analyse further investment in increasing the griffon vulture colony at Gamla. The various efforts to increase and stabilize the griffon vulture population in Gamla and in wider Israel, such as operating feeding stations or monitoring vulture movements with radio-telemetry, are costly. By comparing costs and benefits and showing the social benefit from ecotourism associated with viewing vultures, we can justify investment in further efforts to protect this species.

\section{Acknowledgements}

This research was supported by the Israeli Ministry of the Environment. We extend our thanks to the chief scientist department at the Ministry, and to the staff of Gamla 
Nature Reserve for their invaluable help. We would also like to thank two anonymous reviewers for their very helpful comments.

\section{References}

Bahat, O. (1998) The way of a vulture in the sky. The Torgos, 25, 5-67. [in Hebrew with English summary]

Bell, F. \& Leeworthy, V.R. (1990) Recreational demand by tourists for salt-water beach days. Journal of Environmental Economics and Management, 18, 189-205.

Brown, G. Jr (1993) The viewing value of elephants. In Economics and Ecology (ed. E.B. Barbier), pp. 146-155. Chapman \& Hall, Victoria, Canada.

CBS (2005) Israeli Central Bureau of Statistics.

Http:/ / www.cbs.gov.il [accessed 15 August 2005].

Clawson, M. \& Knetsch, J. (1966) Economics of Outdoor Recreation. John Hopkins University Press, Baltimore, USA.

Gamla (2000) Management Report. Internal publication. Israel Nature and Parks Authority, Jerusalem, Israel. [in Hebrew]

Garrod, G. \& Willis, K.G. (1999) Economic Valuation of the Environment. Edward Elgar Publishing, Cheltenham, UK.

Hacket, S. C. (2000) The Recreational Economic Value of the Eastern Trinity Alps Wilderness. Manuscript. Humbolt State University, California, USA [http:/ / www.humboldt.edu/ envecon/econ_423/trinityAlps.html, accessed 17 August 2005].

Katsin, M. (2002) Heshev Magazine: Costs and General Information Heshev Information Systems Ltd, Tel-Aviv, Israel. [in Hebrew]

Kolstad, C. D. (2000) Environmental Economics. Oxford University Press, New York, USA.

Lansdell, N. \& Gangadharan, L. (2003) Comparing travel cost models and precision of their consumer surplus estimates: Albert Park and Maroondah Reservoir. Australian Economic Papers, Dec., 399-417.

Mapa (2005) Http:/ / www.mapa.co.il/general/index.asp [accessed 15 August 2005].

Mckean, J.R., Johnson, D.M. \& Walash, R.G. (1995) Valuing time in travel-cost demand analysis: an empirical investigation. Land Economics, 71, 96-105.

Mendelssohn, H. \& Leshem, Y. (1983) The status and conservation of vultures in Israel. In Vulture Biology and Management (eds S.R. Wilbur \& J.A. Jackson), pp. 86-98. University of California Press, Berkeley, USA.

Mundy P., Butchart D., Ledger J. \& Piper S. (1992) The Vultures of Africa. Accorn Books and Russel Friedman Books, Randburg, South Africa.
Navrud, S. \& Mungatana, E.D. (1994) Environmental valuation in developing countries: the recreational value of wildlife viewing. Ecological Economics, 11, 135-151.

Pervolotsky, A. \& Dolev, A. (2002) Endangered Species in Israel: The Red List of Threatened Animals. Published by the Nature and Parks Authority and the Society for the Preservation of Nature, Tel-Aviv, Israel. [in Hebrew]

Shlosberg, A. (2001) Toxicological risks to raptors in Israel. In The Risks of Toxicoses from Pesticides and Pollutants in Raptors and Wildlife in Israel (eds A. Shlosberg \& O. Bahat), pp. 8-29. Proceedings of an International Workshop, Jerusalem Biblical Zoo, Israel, April 9-10 2000. Society for the Preservation of Nature, Tel-Aviv, Israel.

Tristram, H.B. (1885) The Fauna and Flora of Palestine. Palestine Exploration Fund, London, UK.

Ward, F.A. \& Beal, D. (2000) Valuing Nature with Travel Cost Models. Edward Elgar Publishing, Cheltenham, UK.

Willis, K.G. (2003) Pricing public parks. Environmental Planning and Management, 46, 3-17.

\section{Appendix}

The appendix for this article is available online at http:/ / journals.cambridge.org

\section{Biographical sketches}

Nir Becker's main research interests are Cost Benefit Analysis for environmental problems and valuation techniques for conflict resolution.

Moshe Ihbar's main research interests are plant - animal interactions and nature conservation.

Ofer Bahat's main research interests include ecology, physiology, behaviour and conservation of birds of prey, and the biodiversity of desert ecosystems.

Yael Choresh is an environmental educator, developing study programmes in nature conservation and the protection of griffon vultures.

Gil Ben-Noon is the manager of Gamla Nature Reserve.

Omer Yaffe's main study interests are environmental economics and natural resources management. 